the gray will appear in all the offspring, or if the albino were one extracted from a black, the offspring will all be black. The albinos look alike only because they lack one or two color-producing factors. When the lacking factor is supplied by a pigmental animal of any sort, the particular ancestral color appears again. Similarly in poultry the germ cells of an albino plumage, such as the silky has, behave very differently in inheritance from the dominant white as seen in the white leghorn, and this difference in behavior of the two whites corresponds to a difference in their chemical composition. Indeed the fact, that the enzymes of the germ cells and particularly of the egg determine hereditary characters, points the way to the modification of hereditary qualities, and to the production of this or that character at will. Such, at least, is the goal of the investigator.

\title{
THE CHROMOSOME IN THE TRANSMISSION OF HEREDITARY CHARACTERS.
}

By Professor W. J. Spmlman, Washington, D. C.

I cannot help thinking that the committee on theoretical research in heredity is one of the most fundamentally important of all those that have been appointed. There is a disposition in some quarters to look upon theoretical research as something impractical and of little value. The fact is, however, that, when our theories have once been brought into accord with fact, they become of the utmost practical importance. If our committee can work out the actual facts concerning the manner in which hereditary characters are transmitted from one generation to the next, it will have rendered a great service to the men who are attempting to produce improved strains of plants and animals.

It seems to me that we ought to call attention in our report to those points requiring further investigation before a complete theory of heredity can be established. For instance, Wilson and a few other investigators have found an extra chromosome in the nuclei of certain animals. This chromosome does not take part in synapsis and therefore does not divide in the first post-synaptic division, but passes into one of the resulting cells. The two cells thus produced therefore have a different organism. They then split into four, two of which have each the extra chromosome. This chromosome is present only in the germ cells produced by the male. It is believed that when the ovum is fertilized by a male cell not having the extra chromosome the resulting chromosome is female; but if fertilized by the germ cell having the extra chromosome the progeny is male. It is easy to see the importance of this point to the practical breeder of animals. If it can be demonstrated that sex is controlled by the presence or absence of a particular chromosome, it settles for all time the question of sex con- 
trol. We ought to get together what information is now available regarding the relation of this accessory chromosome to sex, and urge cytologists to investigate the subject further.

Here is another very important point in its relation to a satisfactory theory of heredity. Cytologists, a good many of them at least, are coming to look upon the chromosomes as the bearers of hereditary characters. There is no school of cytologists, however, who insist upon an interpretation of the things seen during the growth and division of the germ cells. This introduces great confusion and renders any satisfactory explanation of known results in breeding practically impossible. We ought to point out the relation existing between the synaptic process and the transmission of hereditary characters, and insist that cytologists shall come to an agreement about the facts. If it is once understood that the chromosomes are the bearers of hereditary characters, we may then hope to get cytologists to work on the relation between the different chromosomes in the same nucleus and the different hereditary characters of the organism. I believe that it will finally be possible to work out the complete relation so that we can get a full understanding of the behavior of hereditary characters and thus breed for improved forms with almost as much certainty as the chemist mixes solutions in order to produce a desired compound.

Another subject of very great importance is that of the relation of characters. In Volume II of the American Breeders' Association, you will find a paper by Webber on this subject, in which he shows that certain apparently non-related characters are nearly always transmitted together in breeding corn. He thinks, however, that in a few individuals these characters become separated. If such is the case, it has a very important bearing upon the theory that the chromosomes are the biological units which carry hereditary characters. Bateson of England has given much study to correlation of this kind, and he does not find the splitting apart of correlating characters reported by Webber. He does find, however, that sometimes one or two correlated characters meet a dominant in a cross and thus disappear temporarily. I have already urged Webber to continue his work with corn to ascertain whether the vanished characters are really separated from their partners or are simply covered up by a dominant.

Some hybrids have been reported which do not follow the usual Mendelian laws. There are two classes of them. The first class resembles one or the other parent and its progeny does the same. They, therefore, fail to break up in the second generation as hybrids usually do. The other class is intermediate between the parents but breed true to type from the beginning. Careful cell studies ought to : be made upon these hybrids to ascertain whether the chromosome behavior is normal in them. Such study ought to throw light upon the relations of the chromosomes in hereditary characters.

If the chromosomes bear the unit characters, these chromosomes must, in the first post-synaptic division, be perfectly true to assume alternative positions whereby the paternal half of a bivalent chromo- 
some is just as apt to go to one daughter cell as the other, while the maternal half of the same chromosome must go in a direction opposite to that of the paternal. In some hybrids it is possible to distinguish between the paternal and maternal chromosomes. These hybrids ought to render it possible to determine whether the chromosomes actually might assume different positions in the metaphase of the reduction division. The examination of a large number of cells in such a hybrid would demonstrate whether the position of the chromosome is governed by the law of probability. If such should prove to be the case we have at once established a mechanism in the actual behavior of the chromosomes that will account for Mendel's law. Hybrids such as that produced by Rosenberg between Droseri rotundiflora with 10 chromosomes in the gametes and Droseri longiflora with 20 smaller chromosomes lend themselves to such study admirably, and should be further investigated.

I have outlined above a few of what. seem to me to be the more important problems in theoretical research relating to heredity at the present time. I realize, of course, that every man has his own views, and it may be that other members of the committee will take an entirely different view of our work.

As I said before, this subject of heredity is a vast subject, and the members of the committee I think all recognize that we have a task before us which, up to the present time, we really do not know a great deal about; but if our lives are spared long enough and we persist in the inquiries which we have in view, we hope to accomplish something.

Chairman GRodT. We are next to hear the report of Secretary Hays, who will in connection therewith present certain resolutions which have been considered by the Council and adopted by them for recommendation to this body at the meeting of to-day.

Secretary HAYs. The Council has recommended for passage the two resolutions which follow:

(1) Resolved that the American Breeders' Association urges upon the Congress of the United States and the legislatures of the respective States that they continue their liberal policy of building up educational research in agriculture, including that relating to the production and improvement of plants and animals.

(2) Resolved that the Committee on Eugenics be authorized to organize either as a committee of the American Breeders' Association, or as a separate society. The American Breeders' Association, however, desires to express the opinion that since the principles of heredity seem to be common to all plants and animals, including man, and since the data derived from the study of one kind of organism will be of importance in the study of other.organisms; and since the greatest advance is to be expected from the widest co-operation; it would seem appropriate and desirable that the Committee on Eugenics should work in connection with the Animal Breeders' Association. 